\title{
Octafilar Helical Antenna for Portable UHF-RFID Reader
}

Regular Paper

\author{
Saber H. Zainud-Deen, Hend A. Malhat ${ }^{1}$ and Kamal H. Awadalla \\ Faculty of Electronic Engineering, Minoufiya University, Egypt \\ * Corresponding author E-mail: er_honida@yahoo.com \\ Originally published in the International Journal of Radio Frequency Identification \& Wireless Sensor Networks, ISSN $1847-9812$
}

(C) 2012 Zainud-Deen et al.; licensee InTech. This is an open access article distributed under the terms of the Creative Commons Attribution License (http://creativecommons.org/licenses/by/3.0), which permits unrestricted use, distribution, and reproduction in any medium, provided the original work is properly cited.

\begin{abstract}
Octafilar helical antenna (OFHA) is proposed for handheld ultra-high-frequency (UHF) radio frequency identification (RFID) reader. The investigated antenna configuration consists of OFHA placed on reader device in the presence of human hand model. The antenna is designed at UHF band centered at $915 \mathrm{MHz}$. The antenna return loss, axial ratio, gain, co-polarized and crosspolarized field components are calculated using the finite element method (FEM) and compared with that calculated by finite integration technique (FIT) for verification of the simulated results. A comparison between the performance of the quadrifilar helical antenna (QFHA) and the octafiliar helical antenna (OFHA) designed at $915 \mathrm{MHz}$ in the presence of the reader device and human hand model is investigated. The OFHA introduces high gain, high front to back ratio, good axial ratio and omnidirectional coverage.
\end{abstract}

Keywords Octafiliar helical antenna, RFID, Reader antenna, and finite element method

\section{Introduction}

In recent years, radio frequency identification (RFID) in the UHF band (860-960 MHz) has become popular in many applications. These applications include supply chain management, serving the needs of manufacturing, distribution and shipping [1-3]. RFID technology is used for automatically identifying and tracking objects offering best tradeoffs between read range, cost, and size. The RFID system generally consists of the reader, tag, and the system operates in the UHF band. The RFID reader antenna is an important component in RFID system and has been designed with circularly polarized (CP) operation. A CP antenna with a low profile, small size, lightweight, high gain, and high front-to-back ratio is required in a portable RFID reader [4-6]. Antenna with higher gain helps to increase read range for the same transmitted RF power, or equivalently one can decrease the transmitted power to achieve the same range. In compliance with maximum allowed $4 \mathrm{~W}$ or $2 \mathrm{~W}$ effective isotropic radiated power (EIRP) for microwave RFID systems, the latter option is perhaps more valuable as it implies lower power consumption by the transmitter and thus longer battery life.

Handheld antennas are likely to be close to human body. Therefore, for the associated health issue, the high front-to-back ratio can prevent users from exposure to the handheld application. Commercial handheld RFID readers use patch antenna where circular polarization is desired [7, 8]. The patch antennas are narrow 
bandwidth. The radiation pattern of a patch antenna has peak gain at boresight (directly in front of the antenna) which is not always ideal in RFID applications where an RFID reader antenna is centered above the coverage area. Resonant quadrifilar helix antenna (QFHA) and more recently the printed quadrifilar helix antenna are used extensively in satellite communication and GPS applications [9]. Generally, for the QFHA the bandwidth of the antenna is related to the size (in wavelengths) of the cylindrical envelope containing the radiating elements, with the volume and diameter being important parameters. The advantages of this antenna are its cardioids pattern, circular polarization and relatively small size compared to other antennas. In UHF RFID, small low gain helical antennas have been primarily used in their normal mode for readers [10]. A relatively recent work describes the potential use of axial mode helical antennas for readers, but the size and construction of those antennas were impractical for handheld readers [11-13]. A circular polarized QFHA for UHF RFID reader is introduced in [14, 15]. Octafiliar helical antenna (OFHA) was used for mobile satellite handset communication in [16,17]. This paper describes the design of a printed OFHA with uniquely shaped radiation pattern to increase the coverage area. The printed OFHA offers advantages of light weight, low cost, circularly polarized, good axial ratio and omnidirectional radiation pattern. It doesn't need a ground plane, and the environment in the area underneath the OFHA has a relatively small effect on the radiation characteristics.

The antenna is modeled and analyzed using the finite element method (FEM) and the results are verified by that calculated by the finite integral technique (FIT). In this paper, the finite element method (FEM) is used to solve Maxwell's partial differential equations describing an electromagnetic problem subject to proper boundary conditions. The entire volume of the problem is discretized into a large number of tetrahedral which is called the tetrahedral mesh or the finite element mesh. At the vertex of each tetrahedron, the field components tangential to the three edges at each vertex are stored. The normal vector field at the midpoint of the edges is also stored. These stored values are used to estimate the electric and magnetic fields inside the tetrahedral. Maxwell's equations are formulated from the field quantities in the tetrahedral and transformed to matrix equations that are solved by numerical methods. A denser mesh of small discretizations could be used for more precise solution $[18,19]$.

The Finite integration technique (FIT) with the perfect boundary approximation (PBA) is a generalization of the Finite-Difference Time-Domain (FDTD). In this method, the integral form of Maxwell's equations in time domain is discretized instead of the differential ones. The PBA mesh has excellent convergence properties. The simulation doesn't require a huge memory to be carried out. Accordingly, using the PBA mesh is suitable to simulate the large structures as the simulated results can be obtained in a very short time [20,21]. Comparing the PBA with the staircase mesh and the tetrahedral mesh, it is considered the best one in terms of the low memory requirements. The tetrahedral mesh also has excellent convergence properties but it requires large memory and a long computing time if large structures are to be simulated. As for the staircase mesh, it is suitable for simple structures without curved structures as it will not converge in a reasonable computing time. The paper is organized with Section II describes the modeling and construction of the OFHA as part of the reader structure. Section III presents and discusses the simulation results. Finally, Section IV concludes the results in the paper.

\section{Numerical Results}

The OFHA consists of four identical bifilar helices arranged coaxially with $45^{\circ}$ degree separation to each other in space. Fig. $1 a$ shows the structure configuration of half-turn OFHA. One arm of the OFHA called bifilar consists of two diagonally opposite thin strips wound around circular cylinder and form two identical helical elements connected radially at the top. A bifilar element comprises a continuous conductor which is open at the radial center of the bottom end. The two open conductor ends provide the feed terminals for the helix. The rectangular coordinates of any arbitrary point on the bifilar element are given by [19]

$$
\begin{aligned}
& x=R_{o} \cos (u+\pi p / 2) \\
& y=R_{o} \sin (u+\pi p / 2) \\
& z=R_{o} u \tan \alpha
\end{aligned}
$$

where $p=0$ and $p=2$ for two helix arms. $u$ is the angle measured from the $\mathrm{x}$-axis, started from $\mathrm{u}=0$ and ended at $\mathrm{u}=2 \pi \mathrm{N}, \mathrm{N}$ is the number of turns. Ro is the helix radius. For one turn helix $C$ is the circumference $\left(2 \pi R_{0}\right)$, and the spacing between turns $\mathrm{S}=\mathrm{C} \tan \alpha$, where $\alpha$ is the pitch angle which is formed by a line tangent to the helix wire and a plane perpendicular to the helix axis. $H$ is the axial length (NS). The four identical helices compromising the OFHA are fed from the bottom end by a phasing network producing a phase progression of $45^{\circ}$ degrees with the sense of the phasing controlling whether the antenna radiates in the back fire or end fire mode. 


\subsection{OFHA in Free Space}

The OFHA in free space is shown in Fig.8.1a. The antenna is designed to operate in the UHF band with center frequency $915 \mathrm{MHz}$ OFHA radius $\mathrm{R}_{\mathrm{o}}=16.39 \mathrm{~mm}$, the axial length $\mathrm{H}=86.89 \mathrm{~mm}$, and the spacing between turns $\mathrm{S}=$ $2 \mathrm{H}=173.8 \mathrm{~mm}$. A half- turn helix is used without ground plane. In spite of the solid heavy visual look, the antenna was hollow and lightweight [20]. The antenna was wound using $\mathrm{W}_{\mathrm{s}}=2 \mathrm{~mm}$ copper strips on a hollow dielectric core cylinder ( $3 \mathrm{~mm}$ thick walls) and covered with a Radom layer ( $1 \mathrm{~mm}$ thick walls), both made from plastic material of $\varepsilon_{r}=2.5$. The top and bottom ends of the antenna are covered with Radom layer ( $1 \mathrm{~mm}$ thick). The total antenna length is $\mathrm{L}_{\mathrm{a}}=91.89 \mathrm{~mm}$ and radius $\mathrm{R}_{\mathrm{a}}=17.4$ $\mathrm{mm}$. The antenna is fed via coaxial cable at the bottom end of the antenna with feeding gab $\mathrm{g}=2 \mathrm{~mm}$. The four arms are fed by source with equal amplitude but out of phase of $45^{\circ}$ from each other. The antenna has no ground plane.
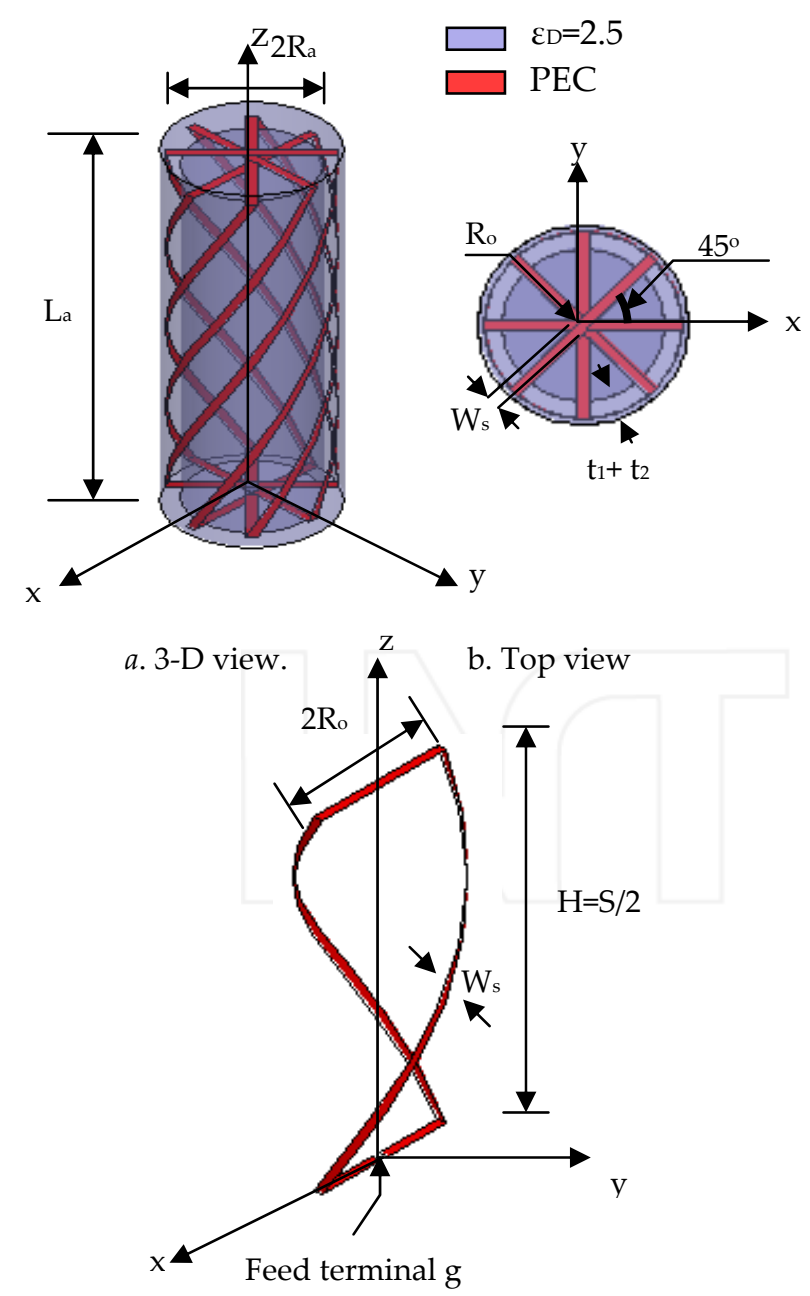

c. Half-turn one bifilar helix

Figure 1. The construction of Octafilar helical antenna (OFHA) in free space.
The frequency response of the return loss for the OFHA in free space is presented in Fig. 2. The $-10 \mathrm{~dB}$ impedance matching bandwidth is $114 \mathrm{MHz}$. The simulated results were calculated using the FEM. The OFHA in free space is resonant over the band from $886 \mathrm{MHz}$ to $1000 \mathrm{MHz}$. The left hand, EL, and right hand, ER, circular polarization field components of OFHA at the resonance frequency $\mathrm{f}=915 \mathrm{MHz}$ are shown in Fig. 3. Omni-directional CP pattern is obtained in $x-y$ plane with high front to back ratio for $E_{L}$ of $27.5 \mathrm{~dB}$ is obtained in $\mathrm{x}-\mathrm{z}$ and $\mathrm{y}-\mathrm{z}$ planes without using conducting ground plane. A 3-D radiation pattern of the OFHA in free space at $915 \mathrm{MHz}$ is shown in Fig. 4. Figure 5 shows the antenna gain and axial ratio versus the angle, $\theta$, in the $x-z$ plane. The half-power beamwidth is $124^{\circ}$. The OFHA introduces gain of 5.4258 $\mathrm{dB}$ and the axial ratio of $0.22 \mathrm{~dB}$ at $915 \mathrm{MHz}$. The angle for $A R<2 \mathrm{~dB}$ is $108^{\circ}$. The frequency response of the antenna gain and axial ratio are shown in Fig. 6 . The gain is varied from $5.317 \mathrm{~dB}$ to $5.439 \mathrm{~dB}$, while the axial ratio changes from $0.0644 \mathrm{~dB}$ to $0.319 \mathrm{~dB}$. The OFHA offers relatively constant gain and axial ratio over the whole entire frequency band. The radiation efficiency of the OFHA is $76 \%$ at the resonance frequency of $5.8 \mathrm{GHz}$.

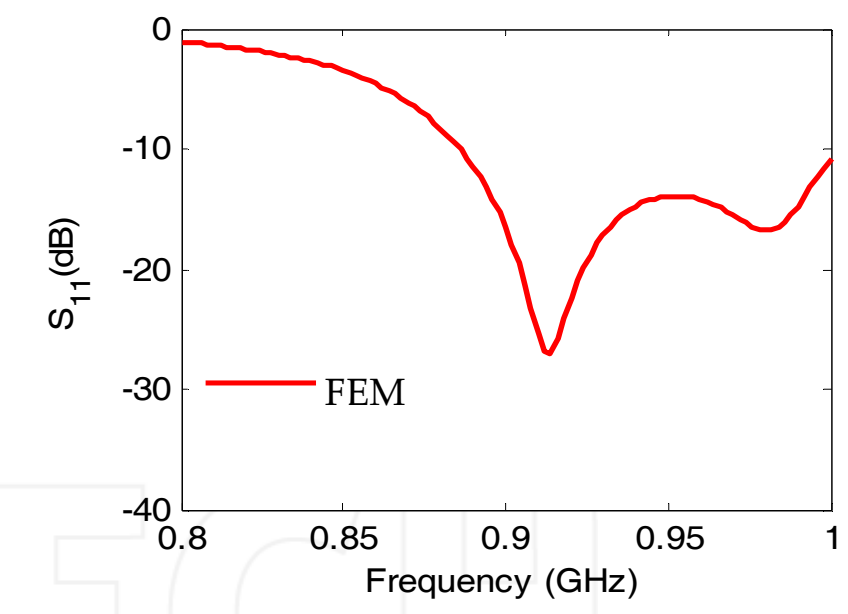

Figure 2. The return loss of the OFHA versus frequency in free space. 

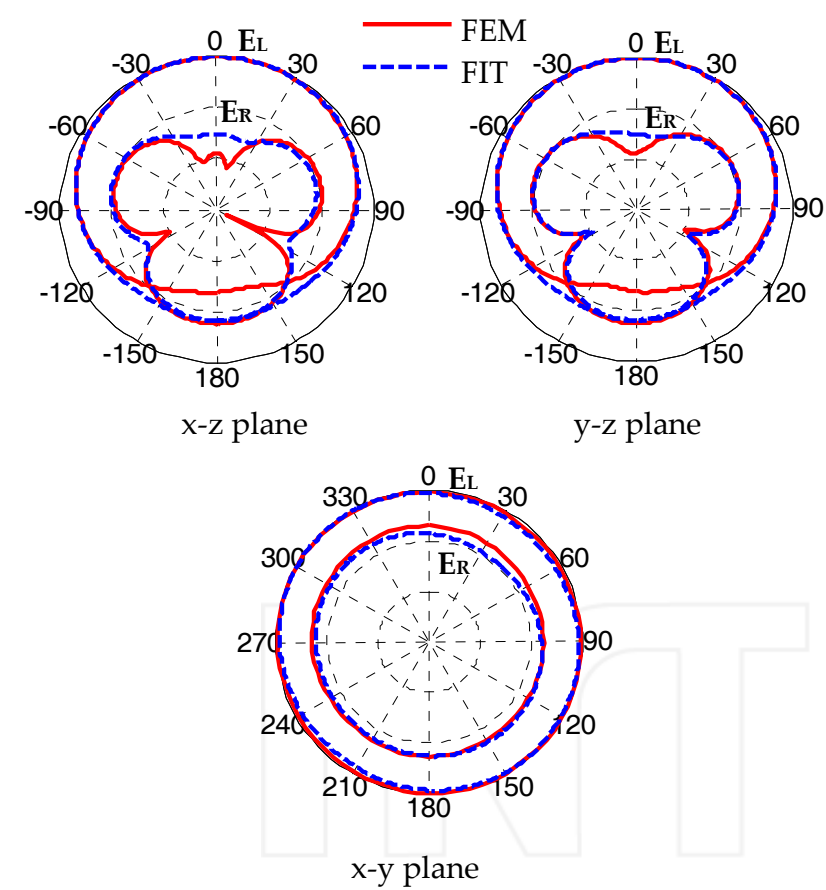

Figure 3. The polarization patterns of the OFHA in free space at $\mathrm{f}=915 \mathrm{MHz}$
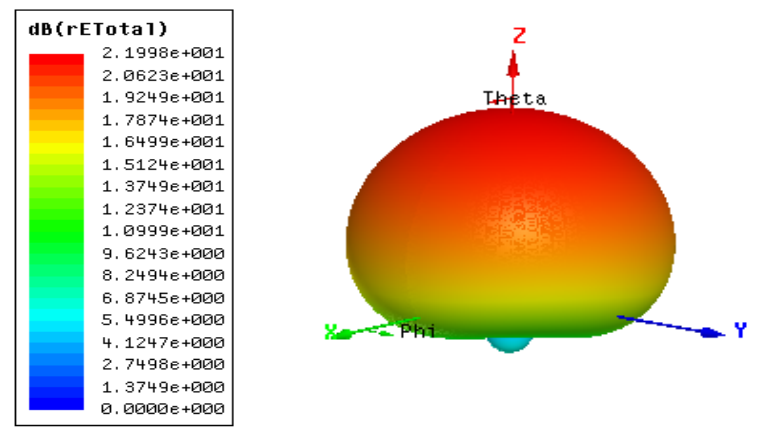

Figure 4. The 3-D radiation pattern of the OFHA in free space at $915 \mathrm{MHz}$.

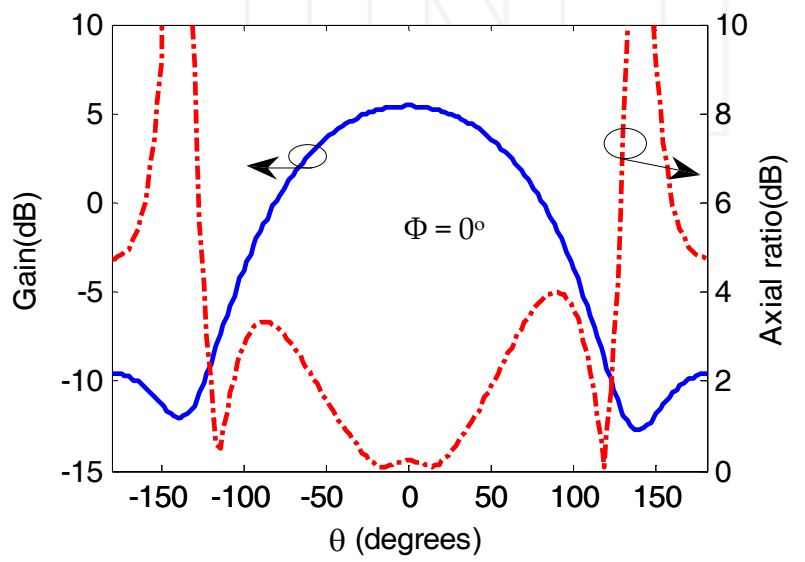

Figure 5. The Gain and axial ratio of the OFHA versus observation angle in free space.

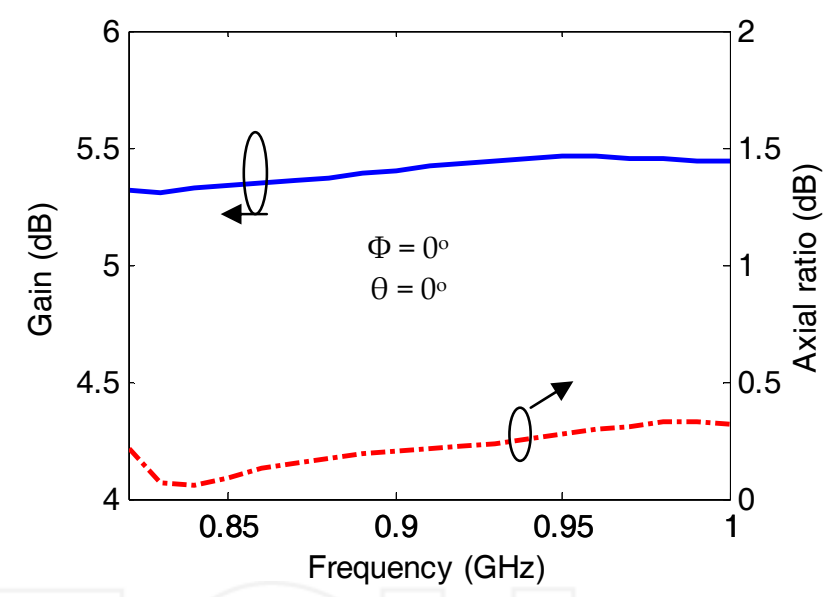

Figure 6. The Gain and axial ratio of the OFHA versus frequency in free space.

2.2 OFHA Placed on a Reader Device in the Presence of Human Hand Model

The proposed antenna model is connected to the reader device in such a way that the radiation characteristics of the OFHA will not be affected by the presence of the reader device and the human hand as shown in Fig.7. The dimensions of a proposed reader device and a homogenous human hand model are presented in Table 1. The return loss of the OFHA in the presence of the reader device and the human hand model is presented in Fig. 8.

\begin{tabular}{|c|c|c|c|c|c|}
\hline $\mathrm{W}_{1}$ & 10 & $\mathrm{~W}_{3}$ & 2.4 & $\mathrm{R}_{2}$ & 0.6 \\
$\mathrm{H}_{1}$ & 3 & $\mathrm{t}_{2}$ & 0.3 & $\mathrm{R}_{3}$ & 0.5 \\
$\mathrm{~W}_{2}$ & 10 & $\mathrm{H}_{3}$ & 5 & $\mathrm{R}_{4}$ & 0.4 \\
$\mathrm{H}_{2}$ & 2 & $\mathrm{~L}_{4}$ & 2.4 & $\mathrm{LF}_{1}$ & 2 \\
$\mathrm{LD}$ & 13 & $\mathrm{~W}_{4}$ & 1.5 & $\mathrm{LF}_{2}$ & 2.5 \\
$\mathrm{t}_{1}$ & 1 & $\mathrm{R}_{1}$ & 0.9 & $\mathrm{LF}_{3}$ & 1.5 \\
$\mathrm{~L}_{1}$ & 4.92 & $\mathrm{~A}_{\mathrm{H}}$ & 10 & $\Phi_{1}$ & $90^{\circ}$ \\
$\varepsilon \mathrm{D}$ & 2.5 & $\mathrm{~B}_{\mathrm{H}}$ & 4.5 & $\Phi_{2}$ & $30^{\circ}$ \\
$\varepsilon \mathrm{H}$ & $20(900 \mathrm{MHz})$ & $\mathrm{LH}$ & 7 & & \\
$\tan \delta_{\mathrm{H}}$ & $0.001 \mathrm{~S} / \mathrm{m}$ & $\mathrm{W}_{\mathrm{H}}$ & 6 & & \\
\hline
\end{tabular}

Table 1. The dimensions of handheld reader device and human hand model (915 MHz). 

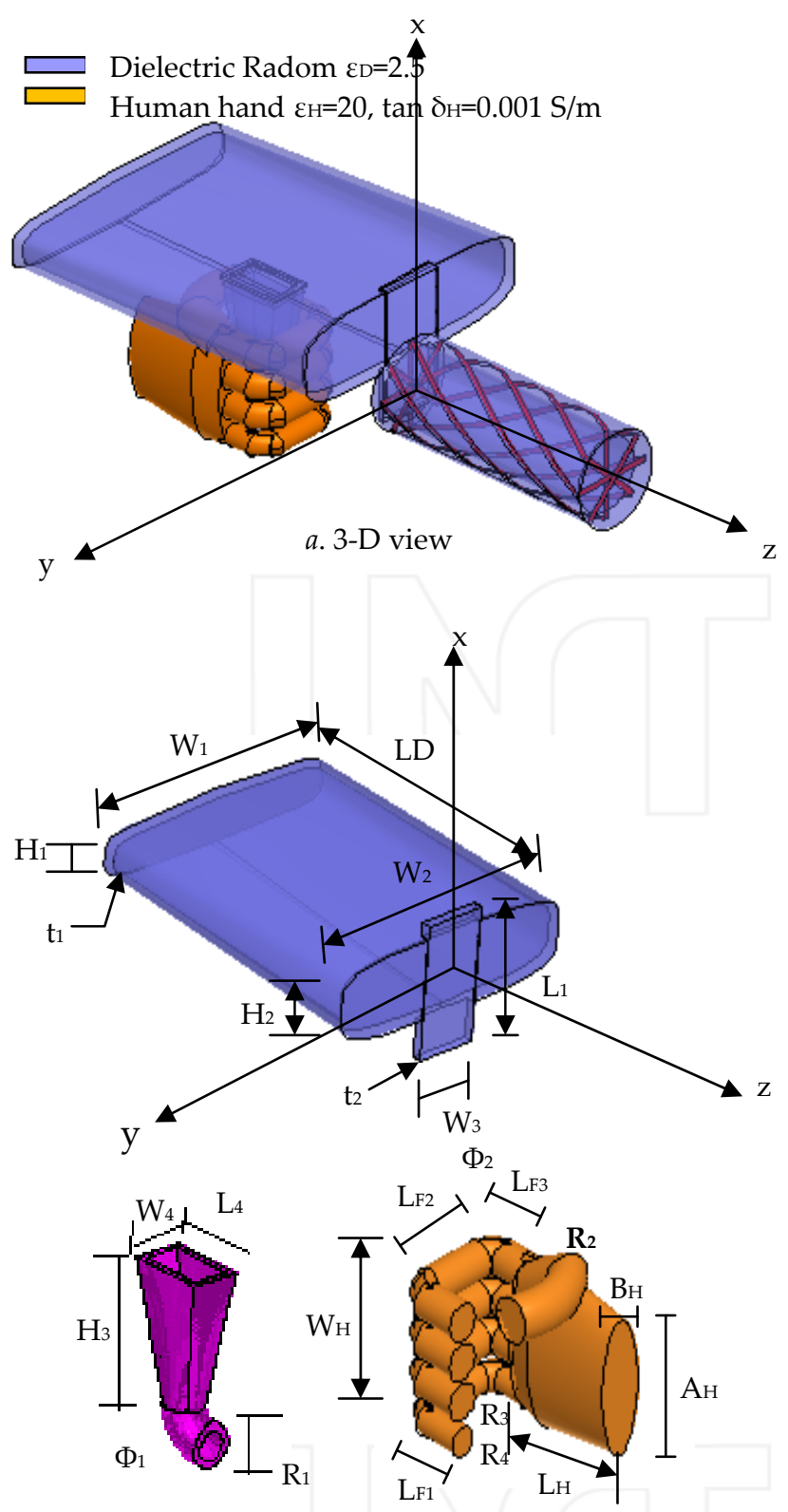

b. Detailed dimensions.

Figure 7. The OFHA antenna placed on reader device in the presence of human hand.

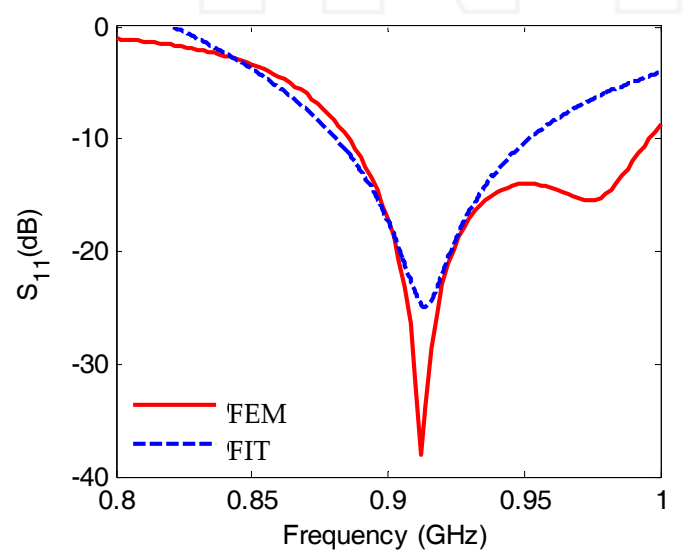

Figure 8. The return loss versus frequency of the OFHA in the presence of reader device and human hand.
The frequency bandwidth is $109 \mathrm{MHz}$ extending from 886 $\mathrm{MHz}$ to $995 \mathrm{MHz}$. The presence of the handheld reader device and a human hand model change the effective dielectric constant of the antenna leads to better impedance matching with the feeding network. The $\mathrm{CP}$ radiation patterns, $\mathrm{EL}_{\mathrm{L}}$, and $\mathrm{ER}_{\mathrm{R}}$, in different planes at 915 $\mathrm{MHz}$ are shown in Fig. 9. Omni-directional CP pattern is obtained in $x-y$ plane and high front to back ratio of 25.17 $\mathrm{dB}$ is obtained in $\mathrm{x}-\mathrm{z}$ and $\mathrm{y}-\mathrm{z}$ planes. Numerical results are obtained using FEM and compared with that calculated by FIT with good agreement between results. A 3-D radiation pattern of the OFHA in the presence of reader device and human hand at $\mathrm{f}=915 \mathrm{MHz}$ is shown in Fig. 10.The antenna gain and axial ratio versus the observation angle, $\theta$, in $x-z$ plane is presented in Fig. 11. The antenna gain is $5.365 \mathrm{~dB}$ and the axial ratio of 0.18 $\mathrm{dB}$. The antenna gain and axial ratio over the frequency band is shown in Fig. 12. It is noticed that, the gain is changed from $5.175 \mathrm{~dB}$ to $5.374 \mathrm{~dB}$ i.e. approximately constant over the frequency band, while the axial ratio is changed from $0.117 \mathrm{~dB}$ to $0.29 \mathrm{~dB}$ i.e. good circular polarization is maintained over the frequency band. The handheld reader device with the human hand model arrangement with the OFHA has no effect on the radiation properties of the antenna as they are placed in the back direction of the OFHA antenna.
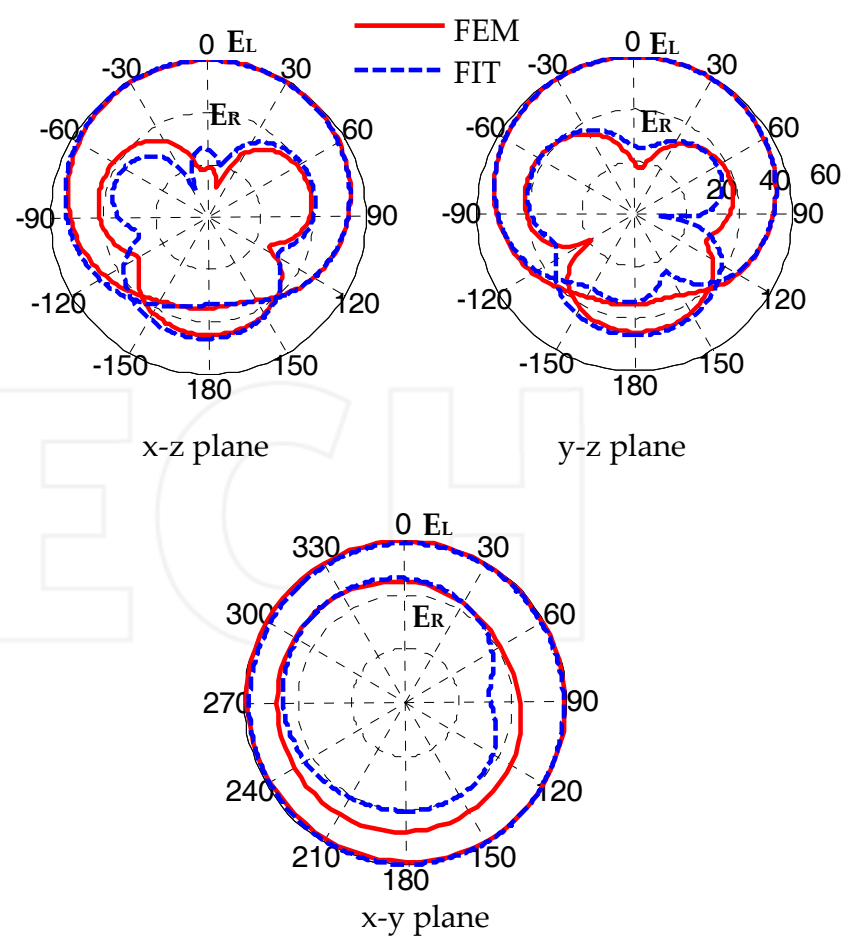

Figure 9. The polarization patterns of the OFHA in the presence of reader device and human hand at $\mathrm{f}=915 \mathrm{MHz}$. 


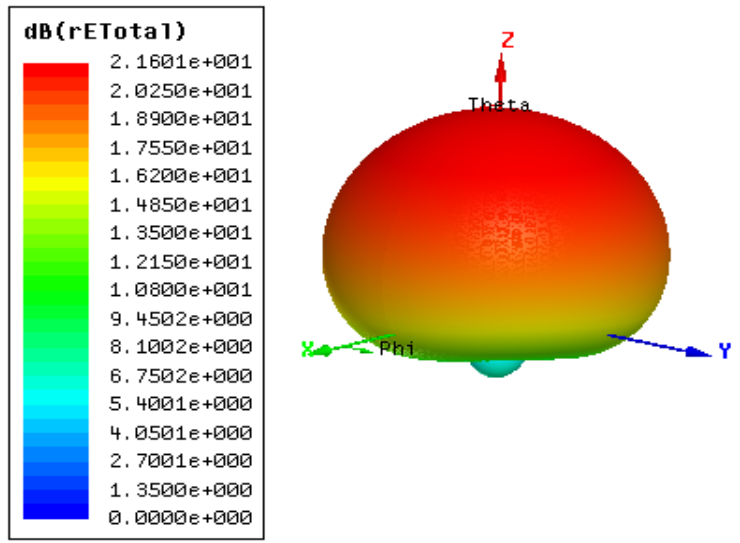

Figure 10. A 3-D radiation pattern of the OFHA in the presence of reader device and human hand at $\mathrm{f}=915 \mathrm{MHz}$.

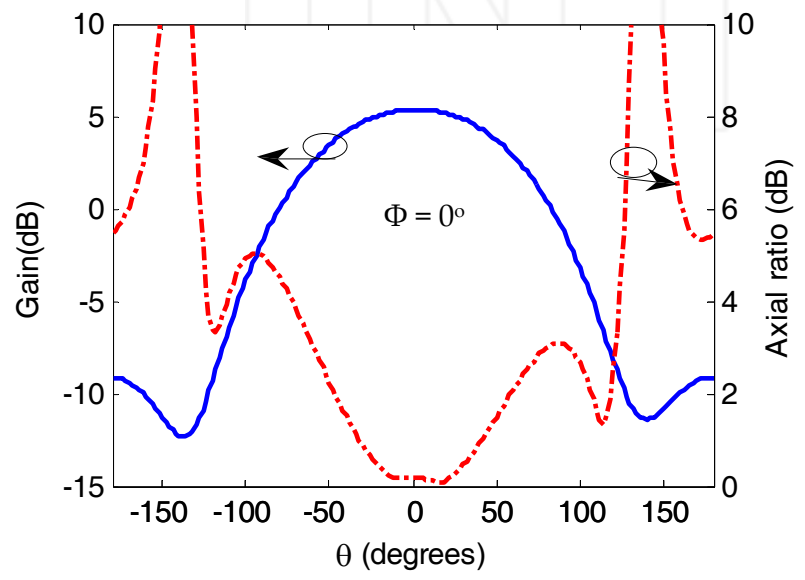

Figure 11. The Gain and axial ratio of the OFHA versus observation angle in the presence of reader device and human hand model.

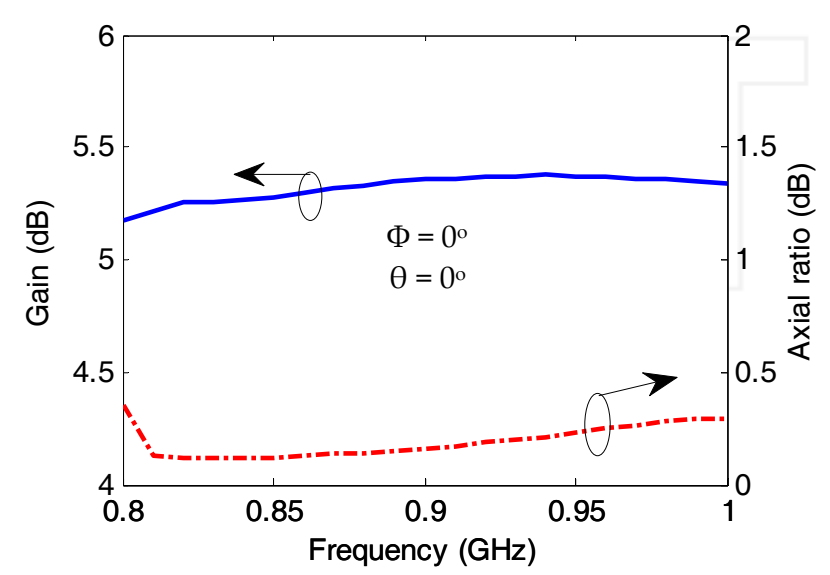

Figure 12. The Gain and axial ratio of the OFHA versus frequency in the presence of reader device and human hand model.
2.3 Comparison Between OFHA and QFHA Placed on a Reader Device in The Presence of Human Hand Model

A comparison using the FEM between the QFHA and proposed OFHA radiation characteristics on the presence of the reader device and human hand model at $915 \mathrm{MHz}$ is presented in Fig. 8.13. The QFHA antenna consists of two bifilar arms in phase quadrateure in orientation and phase shift. The dimensions of the QFHA antenna are optimized for $915 \mathrm{MHz}$ operation. The dimensions of QFHA are $R_{o}=16.39 \mathrm{~mm}, \mathrm{H}=95.9 \mathrm{~mm}, \mathrm{La}=100.9 \mathrm{~mm}$, and $R_{a}=17.4 \mathrm{~mm}$. The impedance bandwidth of the OFHA is much better than that of the QFHA. The OFHA has high front to back ratio and more omnidirectional pattern than QFHA as shown in Fig. 13.a. The input impedance of the OFHA is lower than that of the QFHA as depicted in [19] as shown in Fig. 13.b. In this case there is no need for using matching network with OFHA. From Fig. $8.13 \mathrm{c}$ and Fig. $8.13 \mathrm{~d}$, the OFHA introduces improved gain and axial ratio over the UHF frequency band relative to the QFHA.
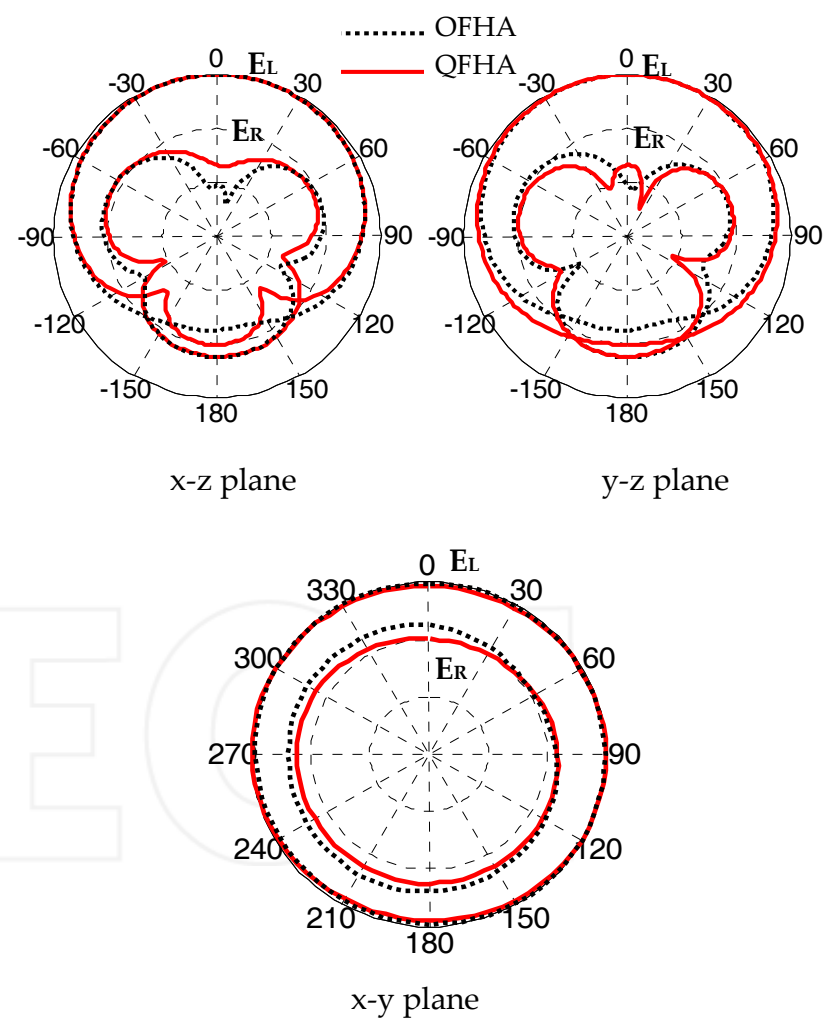

Figure 13a. The polarization patterns of the OFHA and QFHA in the presence of reader device and human hand at $\mathrm{f}=915 \mathrm{MHz}$. 


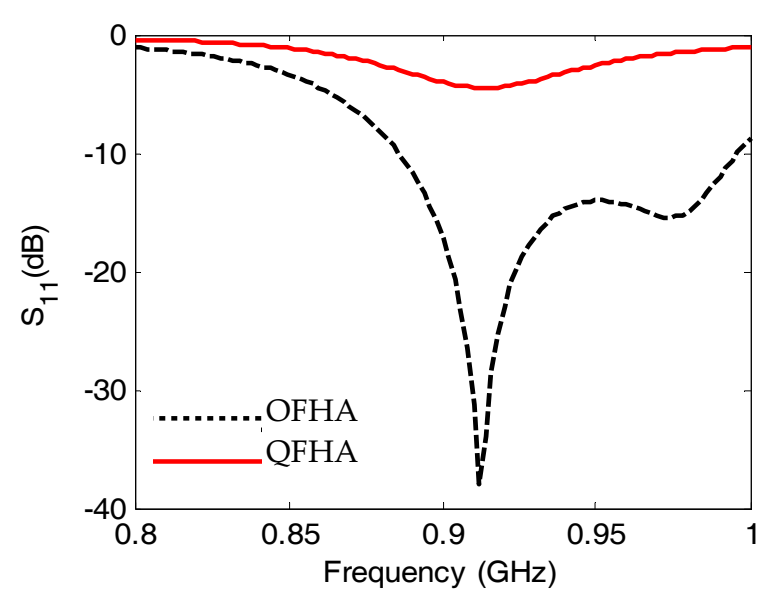

Figure 13b. The return loss versus of the OFHA and QFHA in the presence of reader device and human hand.

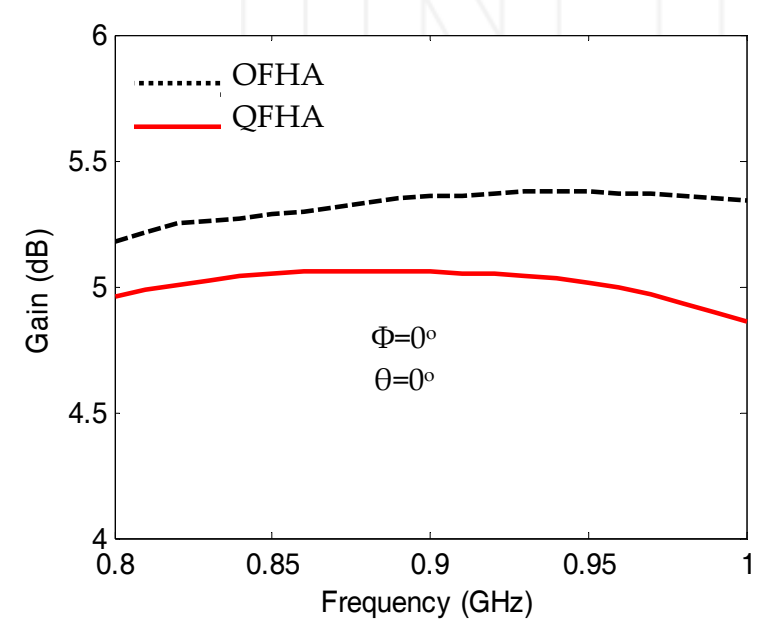

Figure 13c. The Gain of the OFHA and QFHA in the presence of reader device and human hand.

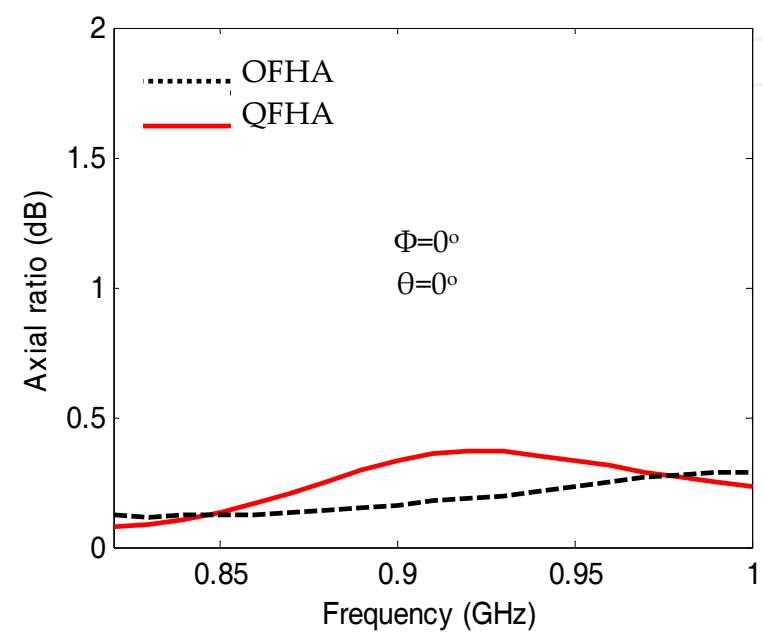

Figure 13d. The axial ratio of the OFHA and QFHA in the presence of reader device and human hand.

\section{Conclusion}

This paper proposes and studies the parameters of an OFHA for handheld UHF RFID reader. The performance of the antenna is investigated using FEM and compared with that calculated by FIT for verifying the results in free space. The OFHA in free space has gain of $5.425 \mathrm{~dB}$ and axial ratio of $0.218 \mathrm{~dB}$ at $\mathrm{f}=915 \mathrm{MHz}$. A simulated model for a handheld reader device in the presence of the human hand is developed. The OFHA is placed on the reader device model in such away that there is little effect on the radiation characteristics of the antenna. The circular polarized field components, return loss, gain and axial ratio of the OFHA are calculated. A comparison between the OFHA and QFHA under the same environmental conditions is investigated. The OFHA introduces high gain, good axial ratio, and high front to back ratio, omnidirectional coverage and good impedance matching compared with the conventional QFHA.

\section{References}

[1] K. Finkenzeller, RFID Handbook: Radio- Frequency Identification Fundamentals and Applications, $2^{\text {nd }}$ Ed., John Wiley E Sons, Inc., England, 2004.

[2] S. Shepard, RFID Radio Frequency Identification, McGraw-Hill, New York, USA, 2005.

[3] G. Monti, L. Catarinucci, and L. Tarricone, "Compact microstrip antenna for RFID applications," Progress In Electromagnetics Research Letters, PIER L, Vol. 8, pp. 191- 199, 2009.

[4] S. A. Yeh, H. M. Chen, Y. F. Lin, Y. C. Kao, and J. Y. Jan, "Single-layer circularly polarized slot antenna for RFID reader application," in Proc. IEEE Antennas and Propagation Soc. Int. Symp., Vol. 1, June 2010.

[5] Y. Lin, Y. Kao, S. Pan, H. Chen, "Bidirectional Radiated Circularly Polarized Annular Ring Slot Antenna for Portable RFID Reader," ACES Journal, vol. 25, no. 3, pp. 182 - 189, March 2010.

[6] M. A. Mangoud, “Design of Circular Polarized Antennas Using Genetic Algorithm Based on Curved Wire Analysis," ACES Journal, vol. 19, no. 3, pp. 77 - 183, November 2004.

[7] F. Y. Kuo, and H. T. Hsu, "Aperture-coupled patch array antenna for microwave band RFID handheld reader," in Proc. IEEE Antennas and Propagation Soc. Int. Symp., Vol. 1, June 2010.

[8] H. L. Chung, X. Qing, and Z. N. Chen, "Broadband circularly polarized stacked patch antenna for UHF RFID applications," in Proc. IEEE Antennas and Propagation Soc. Int. Symp., Vol. 1, pp. 1189-1192, June 2007.

[9] Y. Letestu, and A. Sharaiha, "Multiband printed quadrifilar helical antenna," Electronics Letters, vol. 46, no. 13, pp. 885-886, June 2010. 
[10] T. W. Brown, and S. R. Saunders, "The intelligent quadrifilar helix: a compact MIMO antenna for IEEE 802.11n," in Proc. IEEE Antennas and Propagation Soc. Int. Symp., Vol. 1, June 2010.

[11] J. Choo, H. Choo, I. Park, and Y. Oh, “Design of multi-layered helix antennas for RFID readers in UHF band", in Proc. IEEE Antennas and Propagation Soc. Int. Symp., Vol. 1, June 2005.

[12] C. Su, H. Ke, T. Hubing, "A Simplified Model for Normal Mode Helical Antennas," ACES Journal, vol. 25, no. 1, pp. 32 - 40, January 2010.

[13] C. Su, H. Ke, T. Hubing, "Corrections to 'A simplified Model for Normal Mode Helical Antennas," ACES Journal, vol. 25, no. 8, p. 722, August 2010.

[14] G. I. McKerricher, and J. S. Wight, " Quadrifilar helix antennas for UHF RFID", in Proc. IEEE Antennas and Propagation Soc. Int. Symp., Vol. 1, June 2010.

[15] P. Y. Lau, H. Wong, and E. K. Yung, “Accordion shape monofilar axial mode helix for RFID reader", Electronics. Lett., Vol. 42, No. 11, May 2006.

[16] S. H. Zainud-Deen, N. M. Salem, S. M. Ibrahem, and H. A. Moaafy," Investigation of an octafilar helix antenna," $9^{\text {th }}$ International Symposium on Antennas Technology and Applied Electromagnetics, ANTEM, pp. 542-545, July 2002, Manitoba, Canada.

[17] S. H. Zainud-Deen, N. M. Salem, S. M. Ibrahem, and H. A. Moaafy," Octafilar helix antennas for mobile satallite handsets," in Proc. IEEE Antennas and Propagation Soc. Int. Symp., Vol. 1, June 2003, USA.
[18] J. L. Volakis, A. Chatterjee, L. C. Kempel, Finite Element Method for Electromagnetics : Antennas, Microwave Circuits, and Scattering Applications, Piscataway, NJ, IEEE Press, USA, 1998.

[19] A. C. Polycarpou, Introduction to the Finite Element Method in Electromagnetics, Morgan \& Claypool, USA, 2006.

[20] T. Weiland, "A discretization method for the solution of Maxwell's equations for six- component fields," Electromagnetics and Communications AEÜ, Vol. 31, No. 3, pp. 116-120, March 1977.

[21] M. Clemens, and T. Weiland, "Discrete electromagnetism with the finite integration technique," Progress In Electromagnetics Research, PIER, Vol. 32, pp. 65- 87, 2001.

[22] N. M. Salem, Performance Analysis of Helical Antennas for Mobile Systems Using Moment Method, MSc. Thesis, Faculty of Engineering, Helwan University, Egypt, 2003.

[23] Pavel V. Nikitin and K. V. S. Rao, "Helical Antenna for Handheld UHF RFID Reader," in Proc. IEEE International Conference in RFID, Orlando, FL., $p p$. 169-173, 2010.
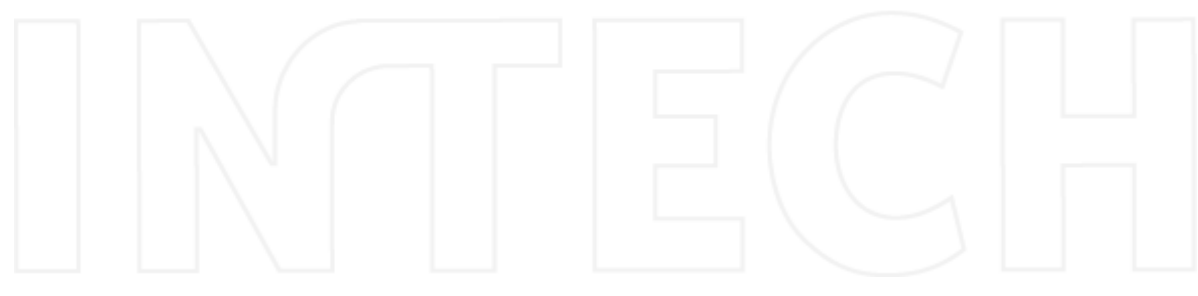